\title{
SOME PROBLEMS WITH HUMAN RESOURCE MANAGEMENT IN BULGARIAN TOURIST ORGANIZATIONS
}

\author{
Viara Slavianska \\ Burgas Free University, Burgas, Bulgaria \\ E-mail: viara_bfu@abv.bg
}

\begin{abstract}
The paper presents results from a study, conducted in the beginning of the year, with the purpose to determine how the human resource management function is realized in Bulgarian tourist organizations and specifically to identify possible problems. The study includes fifty accidentally chosen organizations from the hotel keeping branch, of approximately equal size (from three to five star hotels with over 200 employees). Consecutively are presented the practices, connected with basic activities, composing the human resource management, as well as summary results from the analysis given as recommendations for the management.

It has established as a general conclusion that the practices connected with HRM in the investigated hotels, have some positive sides, but dominate the negative aspects that need an elaboration. The taking of actions directed towards improvement of HRM in these organizations is a consequence from the awareness that: 1) the quality of the tourist product in the hotel keeping is in direct dependence on the quality of the human resource, i.e. the policy for its management and 2) in the conditions of a global economic and financial crisis, not only the survival of the organizations but their prosperity as well, are connected mostly with identification and preservation of the quality part of their personnel.
\end{abstract}

Key words: anti-crisis personnel policy, economical crisis, hotel keeping, human resources, tourism.

\section{Introduction}

Tourism is a basic branch of Bulgarian economy, with chances for quick development and respectively an increasing share in GDP of the country (Andreeva, 2010). But unfortunately Bulgaria could not establish itself as a desiredlattractive tourist destination yet and one of the main reasons for this is that the quality of service in the branch is considerably behind compared to the world standards and the preferences of the contemporary tourist. All studies in Bulgarian resort complexes indicate that the degree of satisfaction from the level of services is lower in comparison with the other competitive countries - Greece, Spain and Turkey, for example (according to data from the Government Agency of Tourism and National Institute of Statistics, 2010).

Having in mind that the tourist product's quality in hotel keeping is in direct dependence on the quality of the human resources in the organization (Gabriel, 1988), the following question arises: is it possible the indications for inefficiency of personnel to represent mistakes of the system for its management or are due to objectively existing circumstances beyond the control of the human resource managers; for example, the deep economical crisis which stirs a striving for survival through inevitable reduction of expenses, including these for human resources (Iliev \& Koleva, 2010).

Provoked by this question, the main purpose of the present study is to determine how 


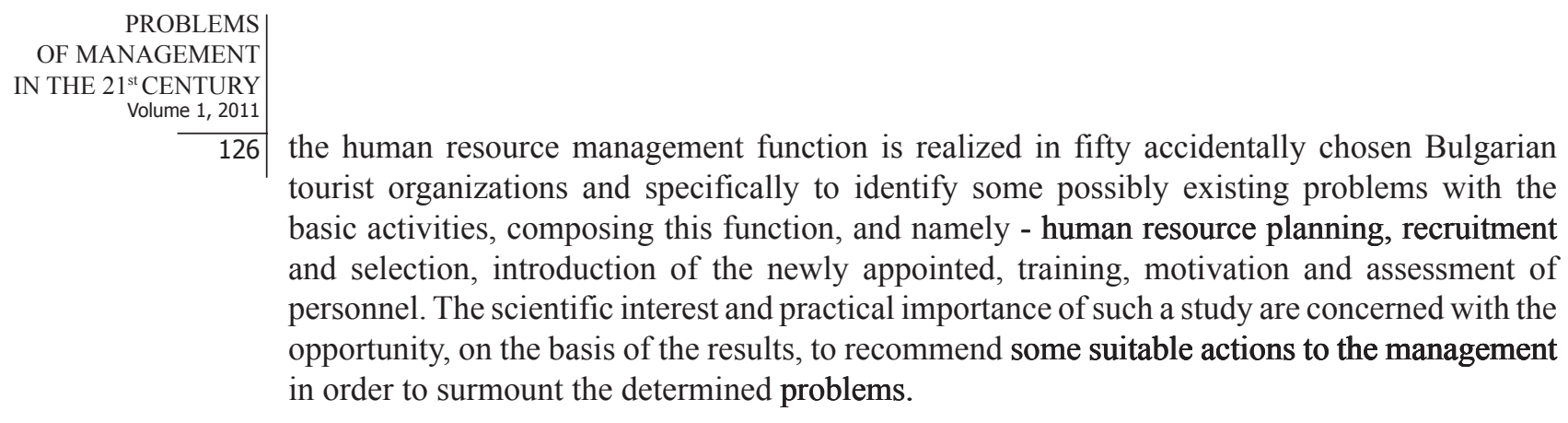

\section{Methodology of Research}

The research followed four basic steps.

Step 1. Questionnaire development. The research instrument, i.e. the paper questionnaire used in the study, was developed in 7 sections containing about 3-4 closed questions, and including the opportunity for free comments on the part of the respondent. Every section was connected with a concrete activity from the HRM function and was respectively operationalized through several empirical indicators. The first section included the existence of a HRM jobldepartment in the organization and its place in the organizational structure, as well as the availability of software for HRM. The second section of questions was connected with the subject, engaged with the human resource planning, as well as the methods used for prognostication of the future needs of personnel. The third section was connected with the provision of the necessary personnel, including who performs this, the preferred sources of candidates (inside or outside), methods for recruitment, who and how develops the job characteristics, the technology of selection, etc. The fourth section concerned the introducing training of the newly appointed employees - its contents and duration. The fifth section had to do with the periodical training of the existing personnel - its frequency, forms and methods used. The sixth section was connected with the practiced forms of employment, base for personnel provision, financial and other stimuli used. And finally, the seventh section concerned the periodicity and technology of the personnel attestation, criteria and connection with the reward system in the organization.

Step 2. Pretesting the survey instrument. The pilot (trial) testing of the questionnaire was done in a sample of 5 people, as a result of which were made slight corrections in its contents.

Step 3. Conducing the survey. The research sample was formed on the principle of the responding (accessible). As the intention was to cover maximum respondents, a great number of hotels with similar characteristics and of approximately equal size (from three to five star hotels with over 200 employees) were chosen from the business guide and their top managers were contacted by phone. Unfortunately, many of them refused an access for different reasons, so the study was conducted only there, where it was possible. Because some elements of the population had no chance of selection and remained 'out of coverage', the sample could not be thought as representative. Hence, because the selection of elements was nonrandom and nonprobability sampling did not allow the estimation of sampling errors, the information about the relationship between sample and population is limited, making it difficult to extrapolate from the sample to the population.

So, a self-completion survey was used for investigation of representatives of the management (top, middle and lower level) and administrative personnel in 50 hotels, located on the Black Sea. The return quota was relatively high - from 300 distributed 289 questionnaires were returned back; moreover they contained sufficiently comprehensive information. The respondents had two weeks at their disposal for completion of the questionnaires, which gave them a relatively good opportunity to consider their answers and to approach conscientiously and thoroughly to the task. 
Step 4. Data analysis. Subsequently the results were statistically processed with MS Excel, as the analysis was limited only to frequency distributions.

\section{Results of Research}

Some of the more significant results from the conducted study are presented very synthesized in seven logically consecutive sections.

Positioning of Human Resource Management (HRM) Function in the Organization

In three of the investigated organizations there exists (although not large) HRM department, which activity is directly submitted to the hotel manager's orders; 28 hotels have a manager or specialist in HRM, and in the rest 19 there isn't such position.
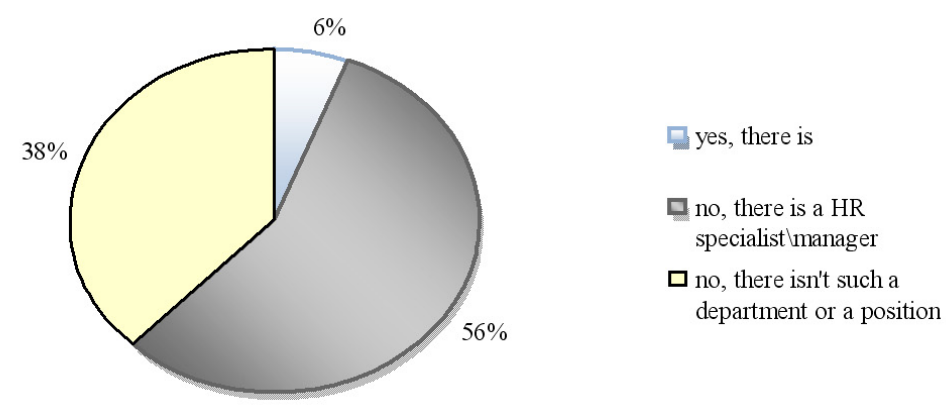

Figure 1: Results from the question "Is there a HR department in your organization?"

The greatest part of the hotels does not have a computer system for HRM (45), some use independent software (4), and only one uses integrated information system.

\section{Human Resource Planning}

The planning of the necessary personnel is duty and responsibility of the immediate managers, according to $93 \%$ of the respondents; in the rest cases it is considered as an engagement of the HRM specialists, performed in a close collaboration with the hotel manager and the managers of the other departments.

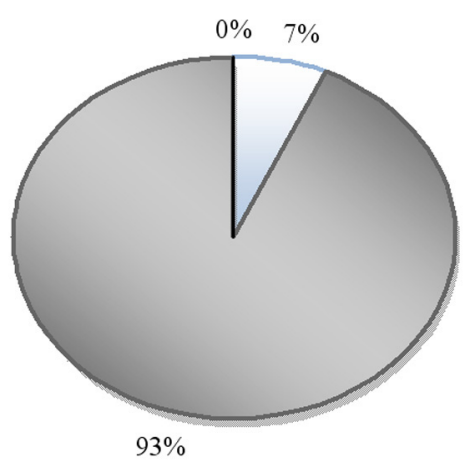

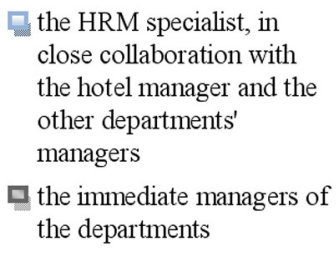
close collaboration with the hotel manager and the other departments' managers

$\square$ the immediate managers of the departments

$\square$ the hotel manager alone

Figure 2: Results from the question "Who is engaged with the planning of the necessary personnel?" 


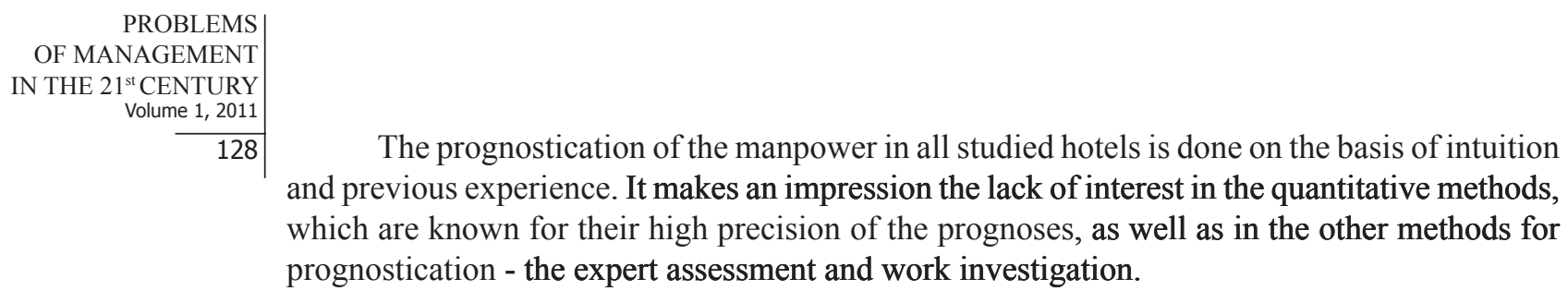

\section{Recruitment and Selection of Personnel}

The recruitment of personnel is done by the immediate manager or the hotel manager, but always after the approval of the executive manager. All investigated organizations give their preferences to the internal recruitment, as far as the permanent administrative staff is concerned. One of the hotels uses so called „card for replacements”, which indicates who can replace whom, the opportunities for promotions. Only if a suitable candidate is missing, the vacant job is advertised on the external market through Internet and local daily papers, without the role of the personal contacts and recommendations from own employees to be underestimated. As far as the seasonal employees and the low qualified jobs are concerned, it is practiced advertisement of the vacant job on the external market, as $40 \%$ of the investigated point out that the hotels prefer to rely on the personnel, employed in previous seasons.

All studied organizations have at their disposal job characteristics (as the Labor code obliges them). According to $14 \%$ of the respondents, they are designed by the HRM specialists, together with the department heads, as for this purpose they use questionnaires, observation and the reports with the employees' assessments, which the direct managers periodically provide. In the rest cases the characteristics are taken already prepared from other similar organizations. The predominant part of the investigated ( $84 \%$ ) affirm, that the selection for the low qualified jobs is done by the direct managers, using the following technology: the HRM specialist examines the documents, gives the approved candidatures to the respective managers, they conduct interviews with the candidates and choose the most suitable one (sometimes together with HRM). Other selection techniques are not practiced (professional and psychometric tests, written exams, graphology, assessment centers and so on). For the high qualified jobs the choice is made by the general manager or the hotel manager.
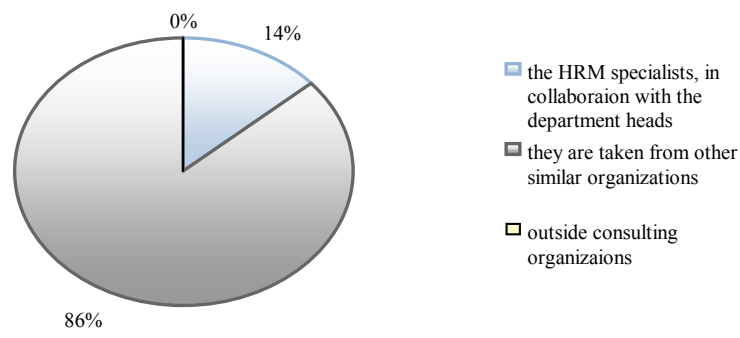

\section{Figure 3: Results from the question "Who prepares the job characteristics in your organization?"}

$89 \%$ of the investigated point out that the direct managers are not trained in the techniques for interviewing. They apply only autobiographical interview (stress or problem solving ones are not practiced). In the selection process are not used personal specifications, as according to $59 \%$ of the respondents the basic selection criteria are the length of practice on a similar position, as well as mastering of at least one foreign language. In the rest organizations, the previous experience and foreign knowledge have only advisable character; obviously they share the wide spread public opinion for the tourist professions as quite easy ones (and respectively 
not too prestigious) or are inclined to invest in training of the newly appointed.

The appointment is expressed in signing of term or termless labor agreements. Only in

four organizations the first two weeks are treated as a test period, after which each of the sides takes its decision for signing of agreement.

\section{Introduction of the Newly Appointed Employees}

According to $83 \%$ from the respondents, the organizations provide some introduction period for the newly appointed employees, as the goals, content and duration of the training may vary, but always it is considered as an engagement of the direct manager (the rest claim that the introduction in the job is done by the colleagues). It may take the form of instructions for anti fire safety, acquaintance with the basic characteristics and opportunities of the hotel, with the specificity and the organization of work, the elements of the working process, the internal regulations, the exact duties on the job, the structure of the department, the colleagues, the work time, etc. There are not used advertising films, written guidancelhandbooks with the basic requirements, rules, firm's traditions and customs. In $60 \%$ of the cases the provided period is one week, and in the other - two weeks.

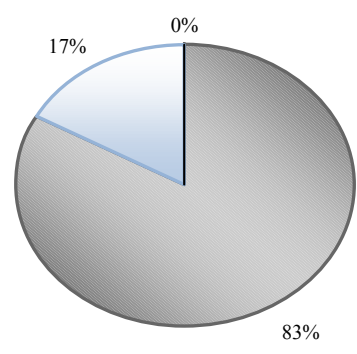

$$
\begin{aligned}
& \square \text { the direct manager } \\
& \square \text { the colleagues } \\
& \square \text { the HRM specialist }
\end{aligned}
$$

\section{Figure 4: Results from the question "Who does the introduction training of the newly appointed employees?"}

But usually this introduction is not practiced for different reasons: it is considered as unnecessary, as the appointed candidate has a previous experience on a similar job or has been appointed in the organization during the previous season, or the dynamics of the activity requires immediate taking up the working duties and there is no time for introduction in the working atmosphere.

\section{Training of Personnel}

Most of the investigated (78\%) point out that their organizations are not inclined to devote resources for the personnel training; from this point of view they prefer to hire staff with the necessary qualification and experience, i.e. ,already prepared”. The investment in qualification increase of the seasonal staff by tradition is almost missing, as it is considered as economically undue. When it is practiced, it is without quitting the job. 


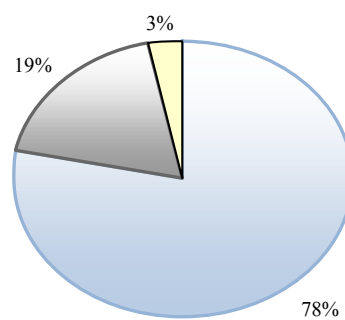

$\square$ no

$\square$ yes, but only for the

managers

$\square$ yes, for the whole

personnel

\section{Figure 5: Results from the question "Does your organization provide regular} training activities for the personnel?"

As far as the permanent staff is concerned, only middle managers are sent from time to time on training in skills for communication, motivation, interviewing and staff selection, conflict management, persuading and team building. Only five organizations invest in language preparation of the personnel as they offer language courses in Russian and German, at two levels; the classes are conducted in suitable time for the employees. One of the organizations carries out training through exchange of experience: there are organized visits in different hotels from the chain, where the employees exchange their experience and impressions with the purpose to standardize the offered tourist product. In the same hotel there exists also a practice to probate and to be trained students of tourism - as an investment in future highly qualified management cadres.

\section{Motivation of Personnel}

Having in mind the fact that the information concerning the financial rewards in Bulgaria is considered as confidential, this part of the questionnaire does not provide quite comprehensive (and realistic) data for the study. It is also supposed that the employees are not inclined to give information that is contrary to the Bulgarian legislation.

All the investigated organizations practice as a form of employment for their administrative personnel labor agreement for indefinite period, and for the rest - temporary agreements. There are not found flexible forms of employment. In all organizations the employees are provided on their real incomes, and the extraordinary and additional work is paid.

The financial stimulation for achieved results is realized in the form of bonuses to the salary in all the studied organizations. The seasonal staff is stimulated through a supplement and proportion from the monthly earnings of the enterprise and through many social gains - free sleeping accommodations, feeding, uniforms, etc. Unfortunately, according to $67 \%$ of the investigated, the employees are not clear about the amount of the bonus, nor yet about the regularity of its receiving.
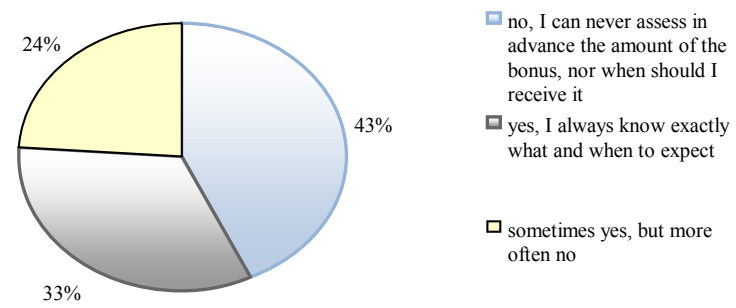

Figure 6: Results from the question "Are you clear about the amount of the bonus, which you receive to your monthly salary?" 
In none of the hotels there are practiced rotation, job enlargement or enrichment, as well as autonomous working groups. Most of the respondents ( $73 \%$ ) point out that the organizations periodically investigate their personnel for establishment of factors, connected with motivation and satisfaction (attitude towards work, atmosphere, conflicts, problems, etc.). $83 \%$ of the investigated point out the organizing of team building parties at least once a year. According to $28 \%$ the prize Employee of the monthlyear is used as a motivator as well.

\section{Assessment of Personnel}

All the organizations periodically assess their employees, as according to $9 \%$ of the respondents this happens once in a month, according to $35 \%$ - once in three months, according to $26 \%$ - once in six months, and according to $30 \%$ - once in a year. The technology of attestation is traditional: the forms are filled in by the direct managers and are then given to the top manager, who takes decisions about due actions: discharge, fine, reprimand, bonus to the salary, promotion. In principle, the employee has the right to objections, but this happens almost never. There are used the classical indices volume and quality of the accomplished work, working procedures and standards, labor discipline; there are applied 5 grade or 6 grade systems.

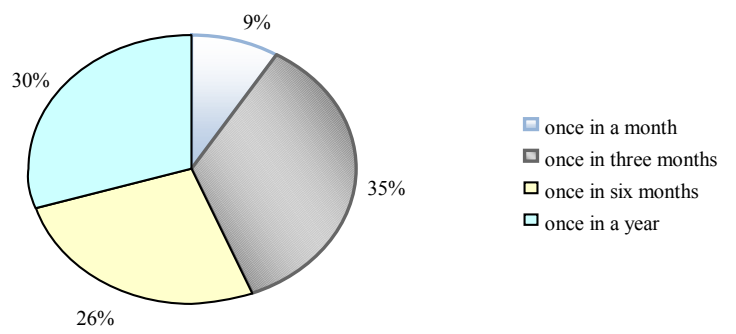

Figure 7: Results from the question "How often is done the assessment of personnel in your organization?"

$20 \%$ of the respondents point out the investigation of tourists as another kind of assessment, on the basis of which punishments or encouragements for the personnel are determined. Usually it is done by the HRM specialists.

\section{Discussion}

\section{Positioning of HRM Function in the Organization}

It is a positive fact that most of the hotels have at their disposal a department or a position, formally engaged with the HRM functions; at the same time, the fundamental decisions about the different activities are made by the linear managers, and the HRM specialists have rather subsidiary and consulting role. The strong decentralization of the function in direction of empowerment of the direct managers respectively increases the requirements to their knowledge and skills in this field.

It should be noted that even where there exists a HRM position, it is not presented in the governing body, i.e. it has not a strategic role, which questions the coordination between the corporative strategies and the HRM strategies and politics. 
Probably the lack of strategic orientation with regard to the human factor determines also the lack of interest to extensive research on the part of the management and giving preferences to intuitive methods of planning. Moreover, the lack of computerized system for HRM or with insufficient opportunities for process analysis creates difficulties for the managers to perform qualitative prognosis activities.

A negative impression is made by the circumstance, that the investigated organizations do not analyze the state of the available personnel and the effectiveness of every job, as well as the reasons for fluctuation (especially of the high-qualified personnel). A considerable facilitation in the planning creates the fact that the hotels prefer to work with tourist agencies which provide the basic share of the tourist flow (mostly German, English and Russian tourists). Thus, on the basis of the concluded agreements, it is reached better prognostication of the tourist services' demand and respectively of the necessary personnel (at least in regard to the vacation tourism, which is seasonal by nature on our Black Sea).

\section{Recruitment and Selection of Personnel}

Recruitment of the human resources from the internal labor market has many advantages and mostly it has a good effect on the motivation and atmosphere in the organization. At the same time, the advertising in Internet gives an opportunity to attract more candidates and respectively more abundant choice, especially in cases when the organization is not willing to rely on former personnel for one or another reason. Despite all, the national advertisement always contains risk of attracting inappropriate candidates from the interior of the country, which look at the offered opportunity for a job as a way to spend one more prolonged vacation at the seaside, do not look seriously at the seasonal employment (especially if they are low qualified) and respectively feel minimum motivation and attachment to the organization.

Not using of personal specifications makes the selection process more difficult, because the interviewer does not have at his her disposal preliminary prepared requirements of the compulsory and recommended professional and personal qualities of the candidate. In this situation the methodical and consistent approach is not impossible and this puts a great amount freedom and bias in the decision making. In terms of the greater impartiality and reducing the risk of mistakes, it is recommended the interviews to be conducted in the presence of or at least after the discussion with the HR manager; the organizations would gain from the panel interviews, i.e. before committee. Currently the influence of HRM specialists over the choice of candidates is quite weak and because of this a serious preparation of the direct managers in connection with selection techniques and procedures is needed. There should not be overlooked also the problems that creates the usage of job characteristics, designed or translated (which is not unusual in international hotel chains, for example) by specialists, who are not familiar with the specificity of the concrete job in the hotel.

Despite that the dominating selection criteria are somewhat logical, a negative impression is made by the neglecting of the influence of personal characteristics, skills and qualities, namely - broad general knowledge, personal charm, communication skills, teamwork skills, initiative, positive attitude towards the client, etc.

\section{Introduction of the Newly Appointed Employees}

The introduction in the job is treated as a key factor for retaining the personnel. But unfortunately, despite that the trainings are formally provided, they are not conducted in practice. Besides this, one week is a quite short period for affiliation with the group and the 
organization, as the crisis of affiliation continues at least one month.

It is recommended the HRM specialists to participate in this process, at least as far as the information, referring the organization as a whole, is concerned. This would facilitate the direct managers and probably would result in a greater chance of practical realization of the trainings.

\section{Training of Personnel}

Definitely the training of personnel is not a priority in the investigated organizations, moreover it has a marked reactive character, i.e. it results from changes in the environment or is directed towards overcoming arising difficulties (a necessity of skills for working with new software, equipment or menus, high turnover, serious problems in the departments, etc.). Probably one of the reasons for this is the inherent to Bulgarian sea tourism pronounced seasonality and stemming from it turnover.

With privileges is used the attraction of prepared personnel or on the job training, which has its undoubted advantages, but requires more attention towards the important components of this process: stimulation of the coach, creation of a favorable environment, assuming responsibility from both sides (which at present are missing).

Most of the trainings are given to the middle management, and it is forgotten that the service of guests is carried out by every one - from the chambermaids to the very top levels in the hierarchy (then it seems that the impressions of the tourists for the organization are formed from their contacts with the least trained, qualified and motivated employees).

Besides this it is necessary the HRM specialists to have a more active role.

\section{Motivation of Personnel}

The motivation of personnel is also a neglected aspect of HRM in the investigated organizations. In the situation of a global economic crisis, adversely affecting the labor price on the market, the labor expenses are an insignificant part of the operative expenses of the hotels (not more than $1 \backslash 5$ ).

The variable part of the reward, intended for a stimulation of the individual contribution, could hardly have any considerable motivating effect because of its uncertainty. In general, motivation is directed towards the satisfaction of primary needs of the employees through financial rewards and permanent labor agreements. It is still assumed that the staff is gaining quite good tips, and therefore there is no need for improving the scheme of rewards.

Unfortunately the moral stimuli are also missing. The jobs are not designed from the positions of satisfaction, i.e. they lack incorporated inside motivators; there are not used the opportunities for rotation as well. As a whole, there are missing efforts towards the satisfaction of achievement, recognition and self realization needs.

The results of the periodical investigations about the motivating factors are not taken into consideration, i.e. have no influence over the policy of rewards. A disadvantage is also the lack of flexible forms of employment.

\section{Assessment of Personnel}

The meaning of the attestation as an official procedure for assessing work is in that to determine the potential of the staff and the needs of its development, as well as to create an opportunity for binding the quality and quantity of work with its payment; if it does not reach these goals, it is absolutely useless.

The results of the attestation in the investigated organizations are used mainly in

PROBLEMS
OF MANAGEMENT
IN THE $21^{\text {st }}$ CENTURY
Volume 1, 2011
133 
PROBLEMS

OF MANAGEMENT

IN THE $21^{\text {st }}$ CENTURY Volume 1, 2011

134 training, reorganizing of the working process or the manpower planning. However it seems that the appraisal of the performance is cursory, it is approached quite formally and routine, which is an indicator that the managers are not aware of its benefits. It is necessary the attestation to be performed constructively, properly and mainly in help for the development of the employee.

Besides this, there are reasons to doubt in the degree of preparation of the direct managers in connection with the techniques for attestation, having in mind the forms and frequency of training, which are offered to them. Probably for this reason they tend to approach this process more dictatorially and conservative - it is not included the self assessment, nor the attestation interview or the valuation forming jointly with the subordinate.

\section{Conclusions}

In the context of the presented results, it develops the assumption that HRM probably bears a great part of the blame for the inefficiency of the personnel and respectively for the low quality of service in the investigated organizations from the tourist branch. With minimum exceptions, concerning mostly representatives of international hotel chains, the situation has a great number of negative dimensions. The hotels have difficulties with finding a qualitative staff and can not overcome mistakes in the service, caused by the shortage of social and other skills in the employees. At the same time, the labor relations are often unfair and sometimes illegal as well (untimely salary payment, working without a labor agreement, provisions on minimum working salary, etc.) There are serious problems with turnover, which give indications for a low quality of the working life and in any case have negative consequences for the organization.

Although there exist positions, formally engaged with HRM function, they do not have a strategic significance. The delegation of activities, connected with personnel management, to the linear managers, is confronted with their lack of relevant skills for designing adequate job characteristics and personal specifications, for conducting a quality staff selection, including the application of reliable and valid instruments, for making appropriate programs for motivation and training, for holding successful attestations, etc. At present the basic HRM activities are carried out mainly as a binding administrative process, devoid of every logical commitment. There are apparent serious gaps and even flagrant errors in the realization of all activities, composing this function.

Undoubtedly the global financial and economical crisis, in which Bulgaria is, leaves its imprint on the tourist branch, as it causes a constant drop in the hotel incomes; this provokes a natural strive for survival through reduction of the expenses, including the ones connected with HRM. In this sense, the crisis somewhat explains, but does not excuse the applied approach to the personnel in the investigated organizations. One of the priorities in the companies' anticrisis policy is a preservation of the so called „quality part” of HR at all levels (management team, specialists, workers); they are the real bearers of the competitive advantage. In fact, the thesis about the quality part of HR is not new, but it is particularly actual nowadays, and at the same time frequently disregarded. The investigated organizations do not identify their quality employees, underestimate the performance assessment, which is at the root of the possible objective establishment of the quality employees, underestimate the causal effect relationship „usefulness and worth of the employee for the organization - valuelprice of the employee", i.e. in practice there are missing mechanisms for retaining these employees. It is especially important the employers not only to realize the significance of motivation, but also to make sense of it, going beyond the scope of the purely financial stimuli, as well as the fact that the investments in personnel training and development are intended to ,produce” quality employees.

The state of the material and technical foundation and the variety in the offers are not key success factors in the hotel keeping for a long time. To be able to attract a more solvent segment 
of the European market, Bulgarian sea resorts should improve first of all the level of service, 1,2011 which is directly connected with more precise employee selection and creating conditions for development and enhancement of their competency and motivation.

\section{References}

Government Agency of Tourism (2011), Available online at http://www.tourism.government.bg/bg/index. php

National Institute of Statistics (2011), Available online at http://www.nsi.bg/SocialActivities/Tourism. htm

Andreeva, M. (2010). The Danube Strategy and the Perspectives for the Development of Tourism, Proceedings of jubilee international scientific and practical conference 'Horizon 2020 to economic knowledge and business", D. A. Tsenov Academy of Economics, Svistov, Bulgaria.

Iliev, Y., Koleva, S. (2010). Pillars of the Company's Anti-crisis Policy in Human Resources Management, Proceedings of VIII international scientific conference "Management and engineering '10", Technical University, Sofia, Bulgaria.

Gabriel, Y. (1988). Working lives in altering. London, Routledge, p.7.

Advised by Milen Baltov, Burgas Free University, Burgas, Bulgaria

Received: May 04, 2011

Accepted: June 05, 2011

Viara Slavianska Assistant Professor, Ph.D., Burgas Free University, San Stefano 62, Burgas, Bulgaria.

E-mail: viara_bfu@abv.bg

Website: http://www.bfu.bg/en/index.php 